\title{
Microstructure Evolution of AA1070 Aluminum Alloy Processed by Micro/Meso-Scale Equal Channel Angular Pressing
}

\author{
Walaa Abdel-Aziem ${ }^{1,2,}$, Atef Hamada ${ }^{1,4}$, Takehiko Makino ${ }^{3}$, and Mohsen A. Hassan ${ }^{1,5}$ \\ ${ }^{1}$ Egypt-Japan University of Science and Technology, P. O. Box 179, New Borg El-Arab City, \\ 21934, Alexandria, Egypt \\ ${ }^{2}$ Department of Mechanical Design and Production Engineering, Faculty of Engineering, Zagazig \\ University, P.O. Box 44519, Egypt \\ ${ }^{3}$ Department of Mechanical Engineering, Nagoya Institute of Technology, Gokiso-cho, Showa- \\ ku, Nagoya, Aichi 466-8555, Japan \\ ${ }^{4}$ University of Oulu, Kerttu Saalasti Institute, Pajatie 5, FI-85500 Nivala, Finland \\ ${ }^{5}$ Mechanical Engineering, Faculty of Engineering, Assiut University, Egypt
}

\begin{abstract}
The Micro/meso-forming of commercially pure aluminum, AA1070, processed at room temperature by equal channel angular pressing (ECAP) with a die channel angle of $90^{\circ}$ through 4 deformation passes has been conducted. Microstructure features, such as grain size, misorientation angle distributions and the developed texture during the four deformation passes of micro/mesoECAP have been investigated by Electron backscattering diffraction (EBSD) technique. Then, hardness measurements over the cross-section of the processed samples were correlated with the EBSD analysis. EBSD scans revealed that extended shear bands (SBs) are formed and represent the microstructural feature induced during micro/meso-forming. Whereas, a non-uniform grain structure consisting of intensive low-angle grain boundaries was obtained in the first pass, a uniform ultrafine-grained structure of high-angle grain boundaries (in the range of 1-2 $\mu \mathrm{m}$ ) was achieved at the fourth pass. Consequently, a significant improvement in the hardness value to $65.3 \%$, with respect to the starting material, was achieved due to the enhancement of the fine grain structure. The texture analysis exhibited that the high plastic shear strain associated with micro/meso-scale ECAP was capable to develop a weak texture in the flow plane compared to the starting texture.
\end{abstract}

Keywords: Micro/meso-forming; Plastic deformation; Equal channel angular pressing; Grain refinement; EBSD.

\footnotetext{
* Correponding author: Walaa Abdel-Aziem at Egypt Japan University of Science and Technology, New Borg El-Arab City, 21934, Alexandria, Egypt

E-mail address: walaa.abdelaal@ejust.edu.eg., Egypt-Japan

Tel: +201069335200
} 


\section{Introduction}

Recently, miniaturization of conventional macro-scale metal forming processes to micro/meso-scale has a significant impact on numerous fields such as electronics, biotechnology and high-precision optics [1, 2]. These micro/meso-forming techniques could be utilized in the fabrication of micro-electromechanical systems (MEMS) parts. This is due to the potential productivity of the micro-forming and the ability to form complex shapes with near-net-shape characteristics and good mechanical properties of the fabricated parts [ 3 ].

Micro/meso-forming of materials have been achieved by different techniques, for instance,

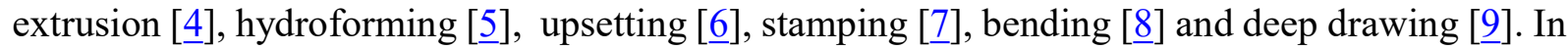
spite of the fact that the principles of macro-scale forming are now well established, there is proof that there are some deviations from the basic manufacturing characteristics, which appear when dealing with micro-scale forming because of the size effects. One of these effects is the grain size effect $[\underline{10}, \underline{11]}$ which becomes a decisive issue in micro-scale forming processes of metallic materials.

Chan et al. [12] studied the deformation behaviour of Al-6061 aluminum alloy by employing micro-compression. They found that the geometry of deformed material becomes irregular with increasing the grain size and decreasing the sample size.

Keller et al. $[\underline{13}, \underline{14}]$ demonstrated the effect of different numbers of grains per thickness of pure nickel thin sheet on the flow stress by conducting tensile tests. It is found that the flow stress tended to deviate from the Hall-Petch relationship for samples with less than about 4 grains across the thickness. Cao et al. [15] found that the extruded micro-pins of CuZn30 brass showed a tendency to curve when using coarse-grained of $211 \mu \mathrm{m}$ in diameter. This behaviour is attributed to the few numbers of grains, i.e. 4 grains across the diameter of the original sample that leads to inhomogeneous deformation.

Peng et al. [7] investigated the micro/meso sheet forming process of AISI 304 stainless steel. They showed that the formability was enhanced with small grain-sized sheet material. Rosochowski et al. [11] conducted micro-extrusion of two different structures of 1070 aluminum, coarse-grained $(300 \mu \mathrm{m})$ and ultrafine-grained (UFG) of $0.6 \mu \mathrm{m}$. In their study, the UFG aluminum billets were deformed using macro-scale equal channel angular pressing (3D-ECAP) die with cross-section dimensions $8 \mathrm{~mm} \times 8 \mathrm{~mm}$ and a length of $46 \mathrm{~mm}$. A special approach was used to prepare a billet size of $1.8 \mathrm{~mm}$ in diameter and $1.0 \mathrm{~mm}$ in thickness for the subsequent micro- 
extrusion. Using UFG structure leads to uniform products with enhanced mechanical properties. Therefore, UFG metals are an attractive candidate to be a viable option for applications in microforming technology. This is because of demonstrating great formability over suitable ranges of temperature and strain rate [16] as well as exhibiting a surface quality, more uniform structure and good mechanical properties for fabricated microparts [1, 18].

It is well established that severe plastic deformation (SPD) techniques are the most promising approaches to obtain bulk materials with UFG structure [19]. Among (SPD) techniques, equal channel angular pressing (ECAP) developed by Segal [20], is the most attractive SPD technique to process UFG metals. From the open literature, intensive work was conducted on pure aluminum and its alloys by ECAP technique using macro-scale [21-23].

Horita et al. [24] investigated the potential of scaling ECAP using Al rod-shaped samples having diameters from $6-40 \mathrm{~mm}$. It is found that the microstructure refinement and the subsequent mechanical properties after processing are independent of the sample initial size.

The study advances expressively from the literature survey that the researchers focused their studies mostly on the traditional ECAP technique. Recently, micro-components and micro-scaled parts are widely used in many industry clusters such as electronics, automobiles, healthcare, aerospace, biomedicine and Micro Electro-Mechanical Systems (MEMS) field. The innovation of this work is production of micro-scale components from the studied material for the stated industrial applications by a novel design of micro/meso-scale ECAP die, as shown in section 2. The micro/meso ECAP die was designed and manufactured by Makino group (one of the present authors), in Nagoya Institute of Technology, Japan. Available studies specify that no work has been carried out to study the microstructure of AA1070 by employing this technique.

The present paper studies the micro/meso-forming of AA1070 alloy by employing the novel ECAP technique developed by Makino group. The deformation behaviour and grain structure features such as the grain size, the misorientation distributions and the texture have been comprehensively studied after micro/meso-scale ECAP experiments in the flow plane using the electron backscattering diffraction (EBSD). The hardness measurements were correlated to the grain structure from each pass and the dislocation density estimated by using X-ray diffraction.

\section{Micro/meso-scale ECAP Principle}


The macrograph and the principle of the micro/meso-scale ECAP technique applied in this work are shown in Fig. 1. It can be seen that the micro/meso-ECAP die is composed of two separated rectangular halves (upper half and lower half) meeting at an angle of $45^{\circ}$. Both halves have the same channel diameter of $1.5 \mathrm{~mm}$.

The two halves are assembled in the grooves of the container, Fig. 1(a). A cover plate is used to avoid displacing the die constituents. The ECAP apparatus dimensions are $40 \mathrm{~mm}$ (length) x 24 $\mathrm{mm}$ (width) x $40 \mathrm{~mm}$ (height), excluding the base plate. These dimensions, $40 \mathrm{~mm}$ (length) x 24 $\mathrm{mm}$ (width) x $40 \mathrm{~mm}$ (height), are for the outer body of the ECAP apparatus. However, the ECAP die has a square cross-section with inner dimensions of $8 \times 8 \mathrm{~mm}^{2}$ and $20 \mathrm{~mm}$ in length. The starting material is $11 \mathrm{~mm}$ in length, hence, two auxiliary specimens of $11 \mathrm{~mm}$ in length are used to assist the deformed sample in getting out of the ECAP die. This design has the advantage of eliminating the burrs that can be easily formed if the die was cut into two halves along the channels. Moreover, it can accomplish a high precision of the sample shape at the contact area of the two channels during the deformation process. Fig. 1(b) shows the procedures of the deformation process of the ECAPed samples. In each proceeding pass, the work sample is rotated by $90^{\circ}$, i.e., route $\mathrm{B}_{\mathrm{C}}$, as shown in Fig. 1(b).

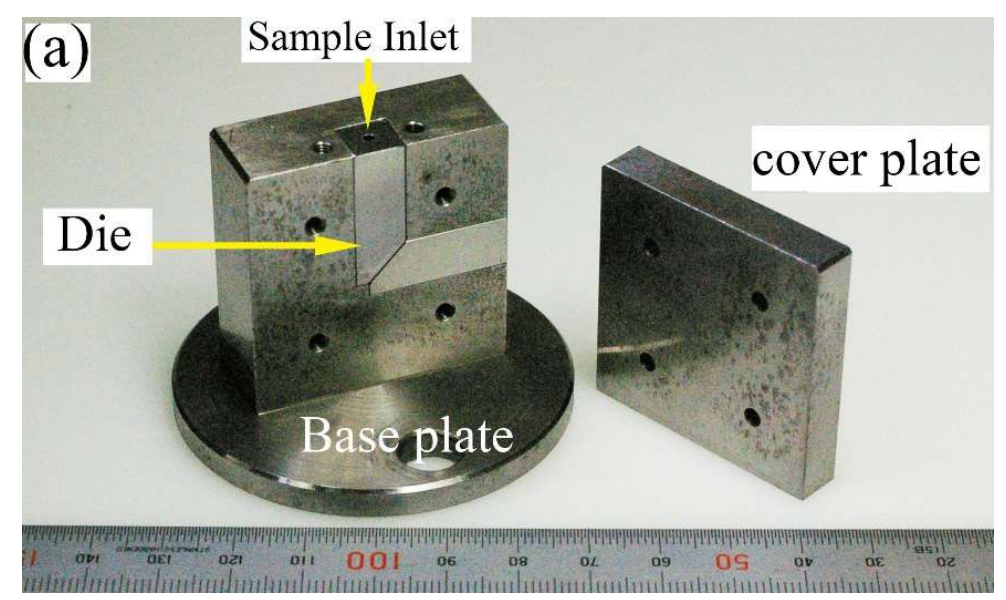




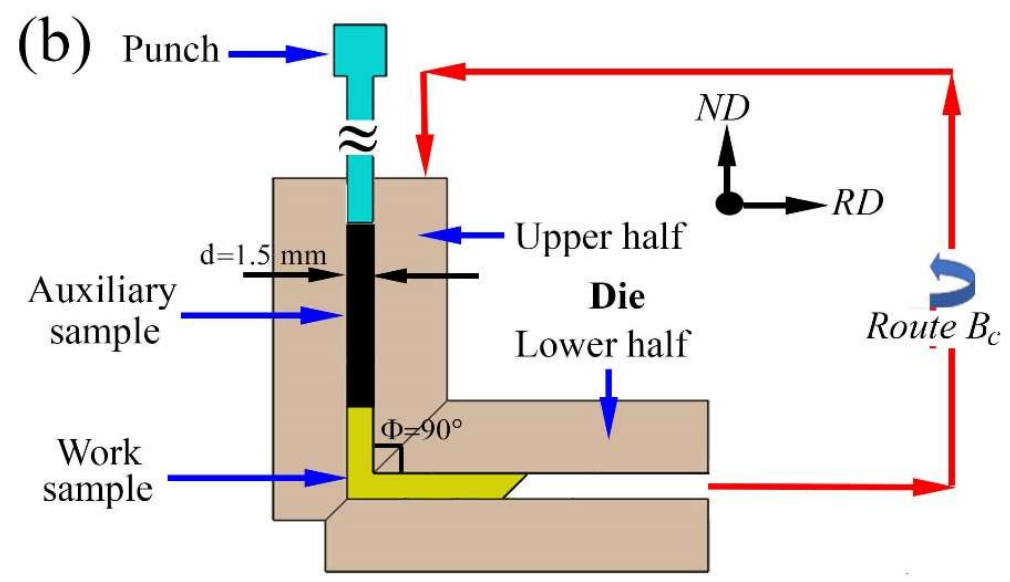

Fig. 1. Micro/meso-scale ECAP die: (a) the employed fabricated die, (b) the Schematic depiction of the die.

\section{Experimental procedures}

\subsection{Material}

In this study, commercial pure aluminum (AA1070) was received in the form of bars of diameter $1.5 \phi \mathrm{mm}$ with a chemical composition (in wt. pet) of $0.25 \mathrm{Fe}, 0.2 \mathrm{Si}, 0.04 \mathrm{Zn}$, and 0.04 $\mathrm{Cu}$. The length of the starting materials for micro/meso-scale ECAP forming was $11 \mathrm{~mm}$. The bars were annealed at $350{ }^{\circ} \mathrm{C}$ to remove the effect of machining processes.

\subsection{Micro/meso ECAP procedure}

The materials have been processed by micro/meso-ECAP deformation up to four passes at room temperature following route $\mathrm{B}_{\mathrm{C}}$, in which the sample is rotated by $90^{\circ}$ counterclockwise about the longitudinal axis in each pass as shown in Fig. 1(b). It was established that route $B_{C}$ is effective in grain refinement in the $90^{\circ}$ die [25]. A lubricant oil of high kinematic viscosity $\left(430 \mathrm{~mm}^{2} / \mathrm{s}\right.$ at 313 $\mathrm{K}$ ) was used to reduce the friction between the sample and the die surface, otherwise, the material tends to get stuck in the channel. The experiments were conducted on a press machine with a load cell of $5 \mathrm{kN}$ and both the force and the displacement were recorded.

\subsection{Characterization}

The microstructural observations and the texture analysis of the ECAP-processed material on the (RD-ND) plane were carried out using EBSD technique in a scanning electron microscope 
(FEG-SEM: Model Jeol JSM-7001F). An accelerating voltage of $15 \mathrm{kV}$ and a step size of $0.3 \mu \mathrm{m}$ on a zone of $150 \mu \mathrm{m} \times 150 \mu \mathrm{m}$ were employed during the EBSD scans. TSL OIM Data Analysis system was employed to process the EBSD data acquisition. Before the EBSD examination, the sample surfaces were ground with standard silicon carbide ( $\mathrm{SiC}$ ) papers with different fineness grits, then mechanically polished through $0.25 \mu \mathrm{m}$ cloth papers. Final mechanical polishing was performed with $0.04 \mu \mathrm{m}$ colloidal alumina (Struers, OP-S) and then followed by polishing using (Struers, OP-U).

Vickers micro-hardness measurements were taken on the cross-section perpendicular to the extrusion direction using the AKASHI MVK-E micro-hardness tester with a load of $200 \mathrm{~g}$ and 15 s dwell time.

\section{Results}

\subsection{Deformation Behaviour of micro/meso-ECAP}

Fig. 2 shows the punch load-stroke curves of the first and final ECAP passes with pressing speed $1 \mathrm{~mm} / \mathrm{min}$. In the first ECAP pass, Fig. 2(a), it can be seen that the average applied load over the stroke during the pressing straining of the material is $0.3 \mathrm{kN}$. With proceeding the deformation, the applied load decreases gradually to reach a minimum value of $0.15 \mathrm{kN}$ as a result of passing out the working sample from the shear zone. With proceeding the deformation to the subsequent ECAP passes, the punch loading curves shift to upper of load increasing. For instance, at the fourth/final pass, the applied load has increased to $0.6 \mathrm{kN}$ over the stroke, as shown in Fig. 2(b). This is attributed to two reasons: the microstructural changes and strain hardening. Both are induced by the associated severe plastic deformation in the micro/meso-ECAP technique.

It is supposed that the displacement has a constant value of $11 \mathrm{~mm}$ after each pass, but it is reduced with the number of passes because the two inclined ends of the processed sample have to be cut for the subsequent pass. This leads to a reduction in the length of the sample after each pass. As can be seen in Fig. 3, the net length of the first pass sample is hardly measured $10.5 \mathrm{~mm}$ without the inclined ends, whereas, after the fourth pass, the length of the working sample is $6 \mathrm{~mm}$. It is noteworthy that the surface of the first pass sample is smooth and keeps it even after the fourth pass. 

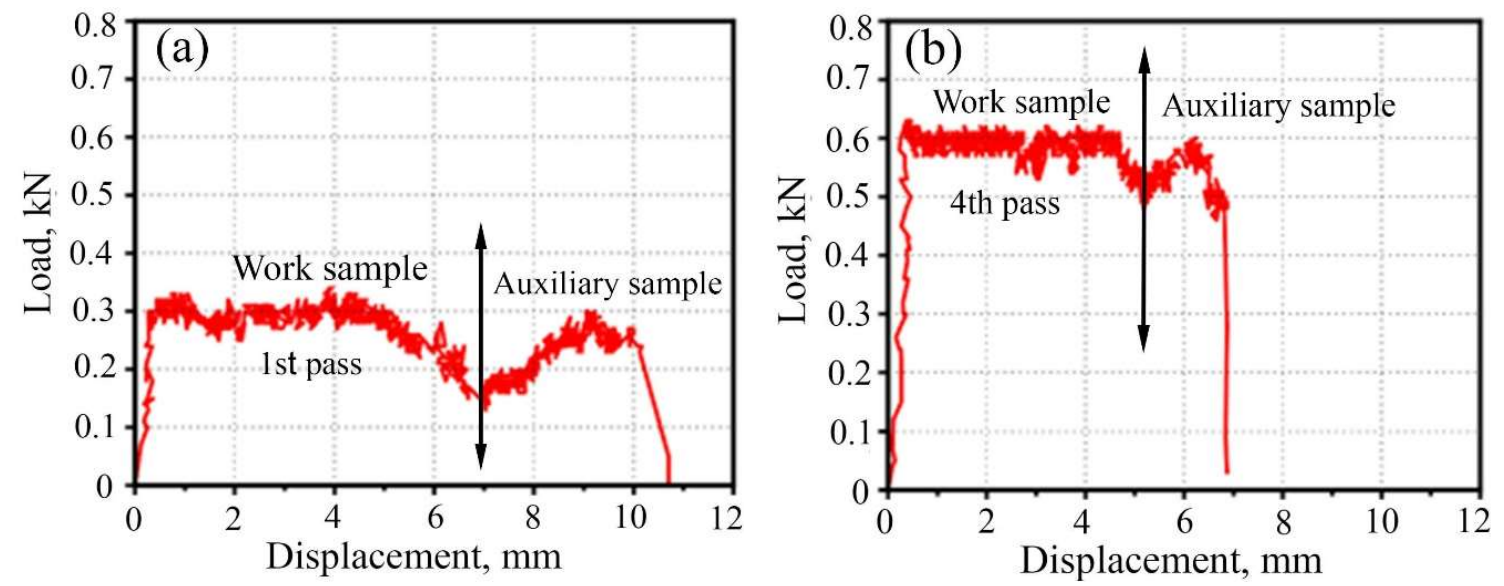

Fig. 2. Load-stroke curves for the ECAPed Al 1070: (a) first pass, and (b) fourth pass.

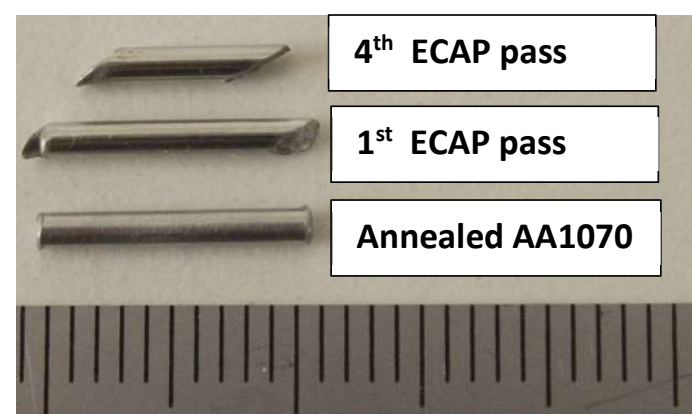

Fig. 3. Typical appearance of the ECAPed AA1070 samples.

\subsection{Microstructural evolution of AA1070 alloy with micro/meso-forming}

The microstructure of the starting material (annealed rods) in the RD-ND plane is shown in Fig. 4. It can be seen that the microstructure is composed of equiaxed large grains with a texture oriented towards $\left(\begin{array}{lll}0 & 0 & 1\end{array}\right)$ and $\left(\begin{array}{lll}1 & 0 & 1\end{array}\right)$, Fig. 4(a). The grain size distribution is clearly varied with larger sizes than $20 \mathrm{um}$, as shown in Fig. 4(b). The average grain size of the annealed AA1070 alloy, i.e., starting material (SM) is $20.4 \mu \mathrm{m}$. The relative frequencies of the boundary misorientation angles, i.e., low-angle $\left(2^{\circ}-15^{\circ}\right)$ and high-angle boundaries $\left(>15^{\circ}\right)$, in the initial microstructure Fig. 4(a) are plotted in Fig. 4(c). It can be seen that the relative frequency of lowangle grain boundaries is very high, about 0.58 , the average misorientation is $\sim 19.6^{\circ}$. This reveals the existence of substructure inside the initial microstructure. It is well established that high angle grain boundaries (HAGBs) are the boundaries with a misorientation angle greater than $15^{\circ}$ and 
low angle grain boundaries (LAGBs), are the boundaries with a misorientation angle smaller than $15^{\circ}$.

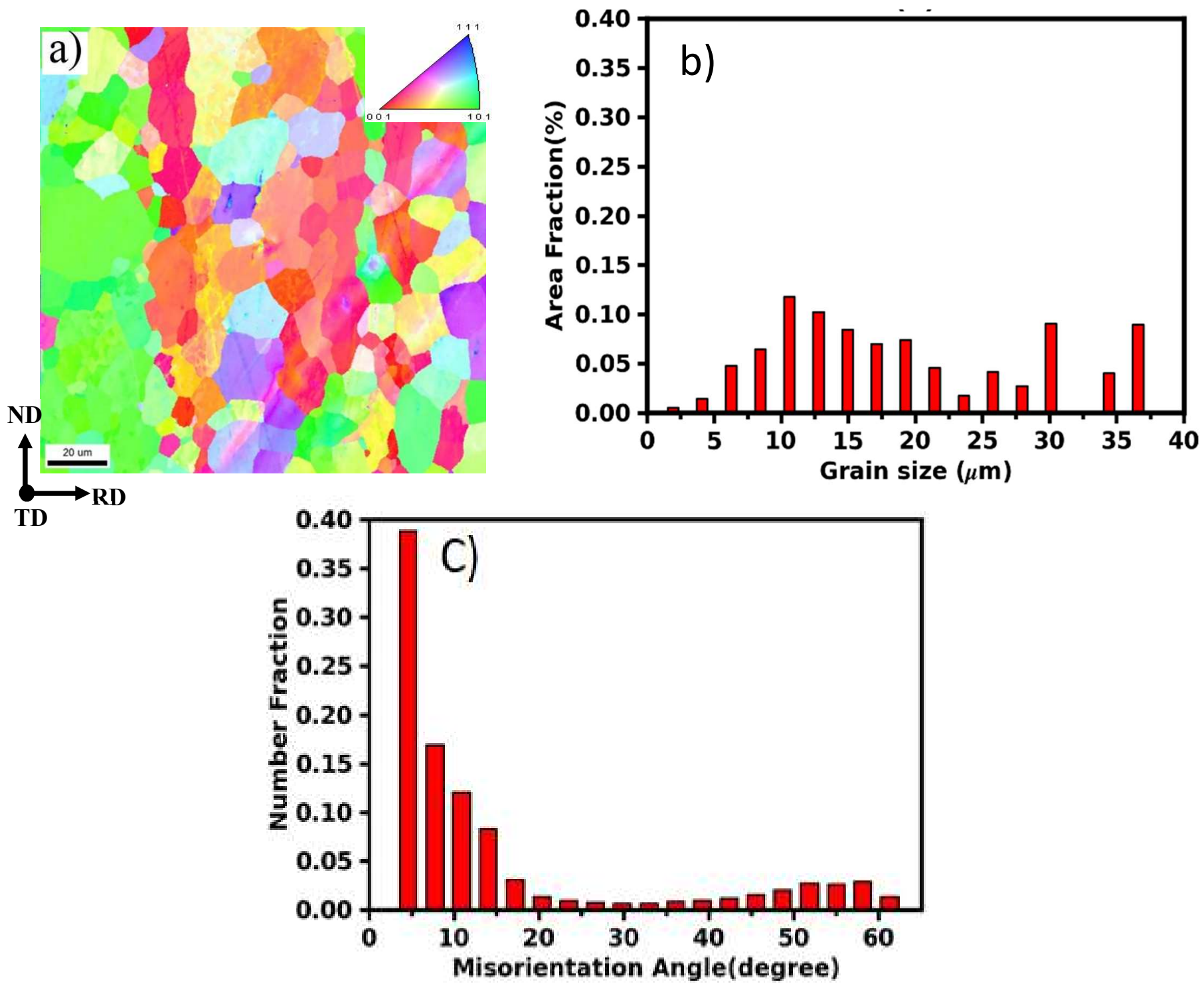

Fig. 4. Microstructure of the starting metal Al 1070: (a) SEM-EBSD-IPF map, (b) the corresponding grain size distribution of (a), and (c) The relative frequencies of the boundary misorientation angles.

The EBSD data were acquired using a $0.3 \mu \mathrm{m}$ step size.

Fig. 5 shows the microstructure and the grain size distribution after the first ECAP pass. It can be seen that the equiaxed grains of the SM have been changed to elongated grains towards the 
shearing direction due to the shearing applied by ECAP process. The direction of the elongated coarse grains is tilted by $\sim 46^{\circ}$, Fig. $5(\mathrm{~b})$.

It is apparent from the observations that this structure displays bandlike features, i.e., shear bands (SB), as indicated by black arrows in Fig. 5(a). These bands consist of elongated substructures as shown from the orientation Euler map, pointed out by the white arrows in Fig. 5(b). In addition, it can be seen that the grain orientation was mainly dominated by the (111) grain orientation (blue color) with some grain orientations of (101)/blue.

The grain size distribution of the deformed structure after 1 pass is shown in Fig. 5(c). It can be seen that most of the grains are smaller than $20 \mu \mathrm{m}$ with few larger grains. The analysis of the EBSD boundary map showed that the average grain size is $\sim 16 \mu \mathrm{m}$. Low-angle boundaries with a misorientation below $15^{\circ}$ were excluded for the purpose of estimating the average grain size.
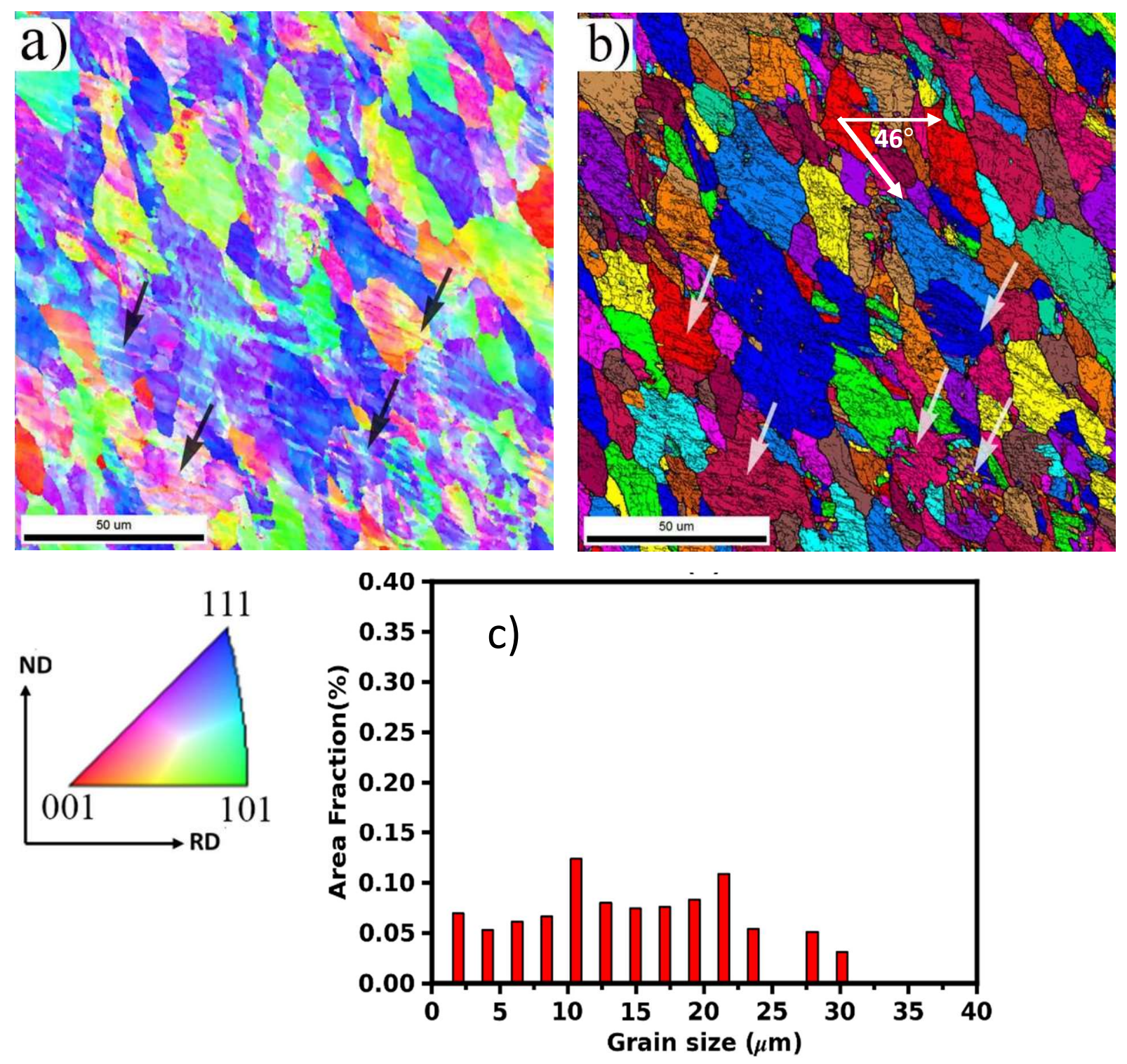
Fig. 5. EBSD maps of the grain structure maps of AA1070 alloy obtained after the first pass of micro/meso-forming: (a) EBSD-IPF map in the (RD-ND) plane, (b) orientation map (using Euler colouring), and (c) the corresponding grain size distribution of (a).

With proceeding the deformation to the second ECAP pass, extended shear bands (SBs) were observed to be the substantial microstructural feature induced due to the plastic deformation in the micro/meso-forming. These extended microscopic shear bands are regions with a highly localized shear strain, i.e., crossing tens of grains, as indicataed by the black arrows in Fig. 6(a). In the open literature, the most significant feature of ECAP deformation in the macro-scale of copper [26] and aluminum [27] is the formation of shear bands. The corresponding Euler orientation map of the microstructure after second ECAP pass displays that most of the fine grains are located in the SB regions, as shown in Fig. 6(b). The grain size distribution for the second ECAP route is shown in Fig. 6(c). It can be seen that the fraction of grain sizes smaller than $10 \mathrm{um}$ has been increased from 0.2 in the first pass to 0.7 in the second micro-forming pass. 

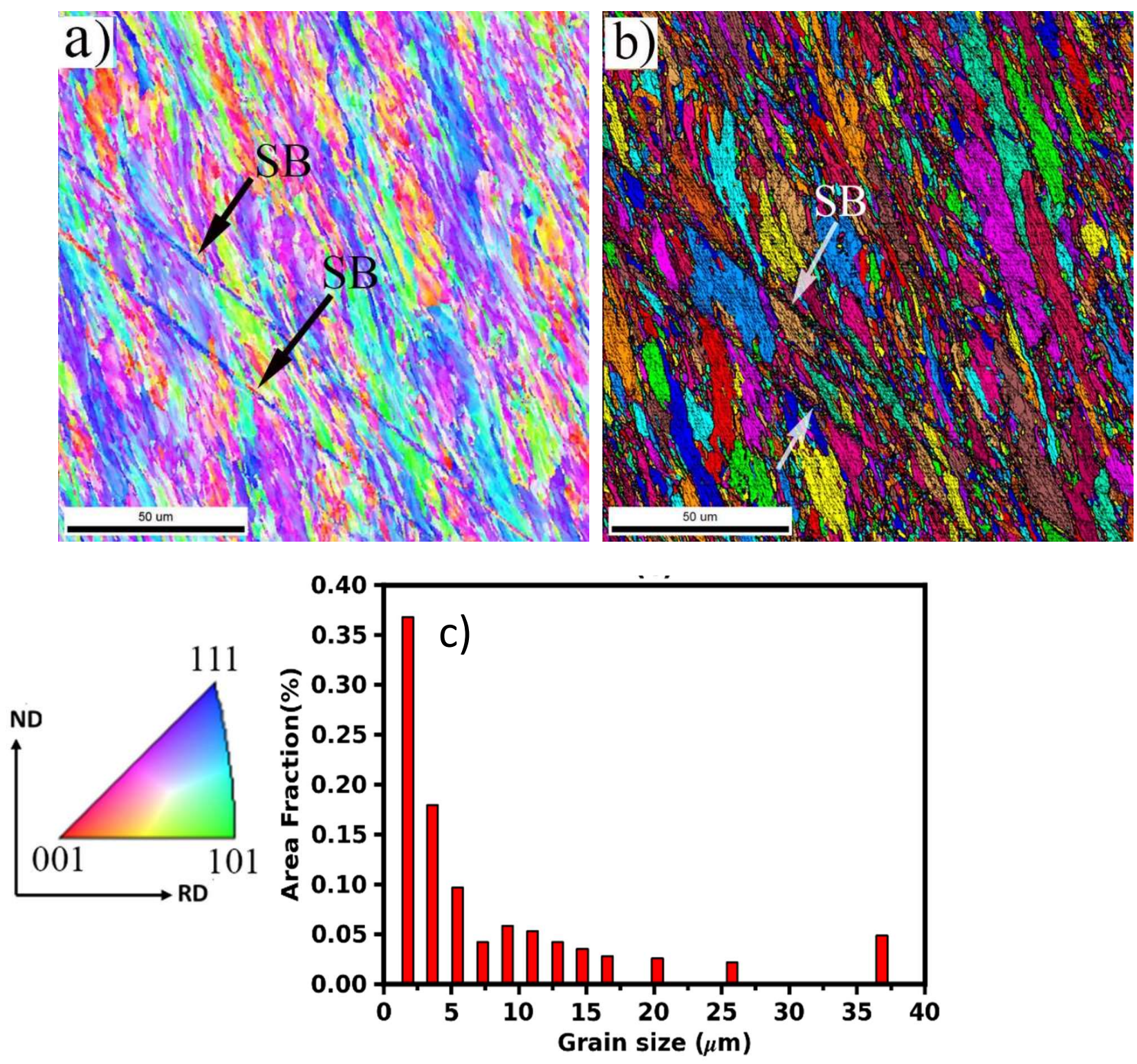

Fig. 6. Grain structure maps of the studied AA1070 alloy obtained by OIM processed by second micro/meso-forming pass: (a) EBSD-IPF map in the (RD-ND) plane, (b) orientation map (using Euler colouring), and (c) the corresponding grain size distribution of (a).

As the micro/meso-ECAP deformation continues to the third pass, more refined grains associated with the density of localized shear bands are enhanced, Fig. 7, as compared with the previous microstructures (i.e., first and second pass). It can be seen that the deformation texture in the formed grains is mainly oriented towards ( $\left.\begin{array}{lll}0 & 0 & 1\end{array}\right)$-red and (1 11 l)-blue. Fig. 7(b) shows the EBSDEuler orientation map of the fine grain structure after the third pass. The corresponding grain size 
distribution is shown in Fig. 7(c). More than 60 pct of grains are within the range from 1 to 3 um; they are equiaxed grains, most likely arising from the mechanism of grain subdivision taking place during heavy deformation of the processed material. This mechanism is similar to that proposed by Hughes and Hansen [28] for HAB formation in rolling and torsion. Sun et al. [29] studied the grain subdivision evolution in aluminum AA1050 during equal channel angular extrusion ECAE. They reported that the grain subdivision is strongly influenced by the original orientation and strain path. Since, during ECAE deformation through route $A$ and $B_{C}$, where different shear planes were involved in consecutive passes, the HAB generation is more effective via the texture evolution.
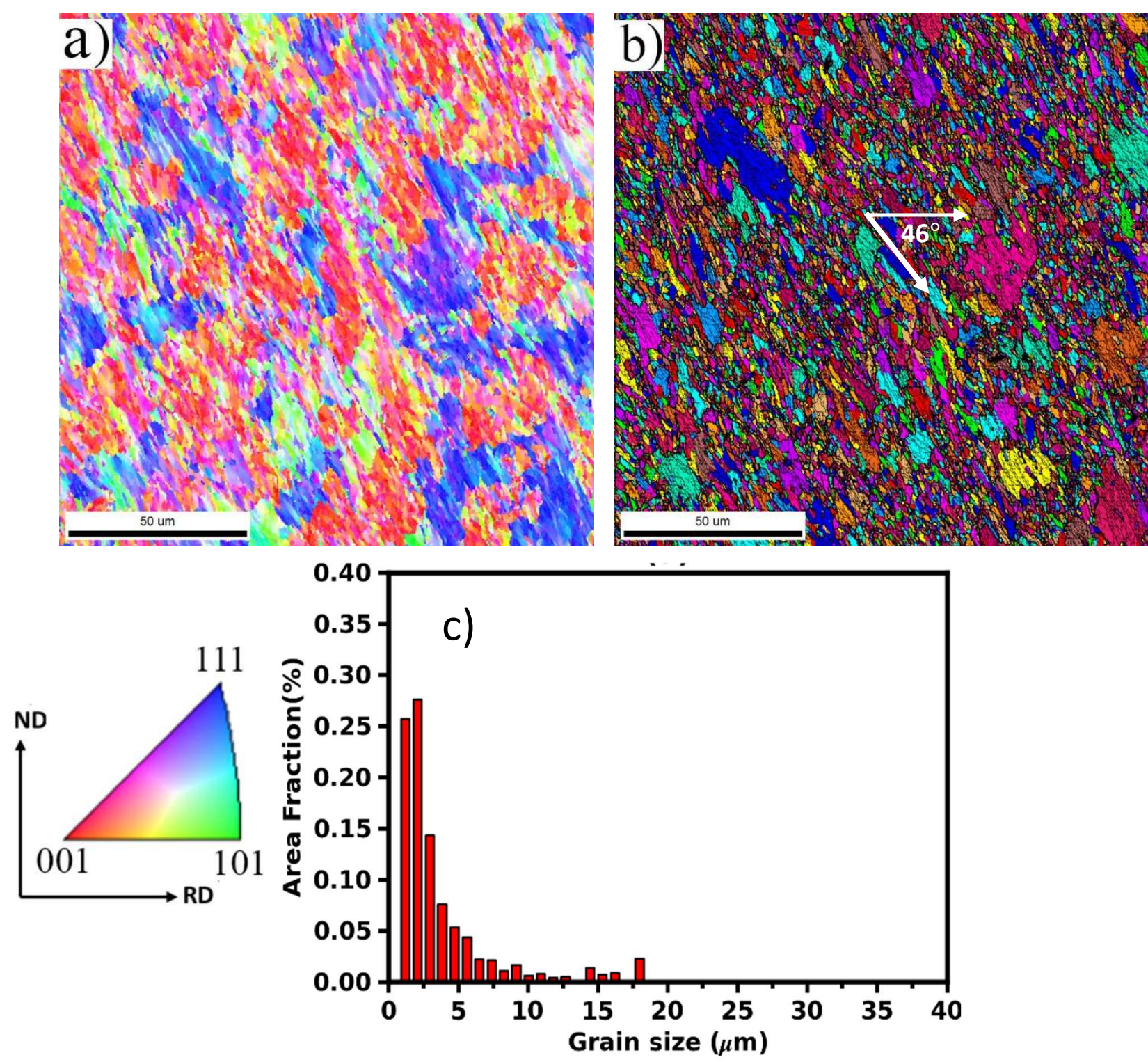
Fig. 7. Grain structure maps of the studied AA1070 alloy obtained by OIM processed by third micro/meso-forming pass: (a) EBSD-IPF map in the (RD-ND) plane, (b) orientation map (using Euler colouring), and (c) the corresponding grain size distribution of (a).

At the final pass of Micro/meso-forming, remarkable grain refinement of the structure is achieved, as shown from the EBSD maps in Fig. 8. In comparison with the structure of the SM, the degree of grain refinement has been significantly increased, i.e., about $\sim 80$ pct of grains are within the range from 1 to $3 \mathrm{um}$ with an average grain size $2 \mathrm{um}$. This indicates the tendency of grains to undergo subdivision during micro/meso-ECAP straining. Hence, it is expected that the microstructural features of the micro/meso-ECAPed samples will affect the strengthening due to grain subdivision and strain hardening by dislocation density.

The microstructural evolution of the micro/meso deformed materials in the present work reveals significant changes with the proceeding number of passes compared with that in the annealed sample. Recently, Fouad et al. [30] applied severe plastic deformation on AA1100 alloy by conducting Multi-channel spiral twist extrusion (MCSTE). They reported that grain refining structure with an average grain size $8.6 \mu \mathrm{m}$ was achieved after 4 passes of MCSTE straining. 

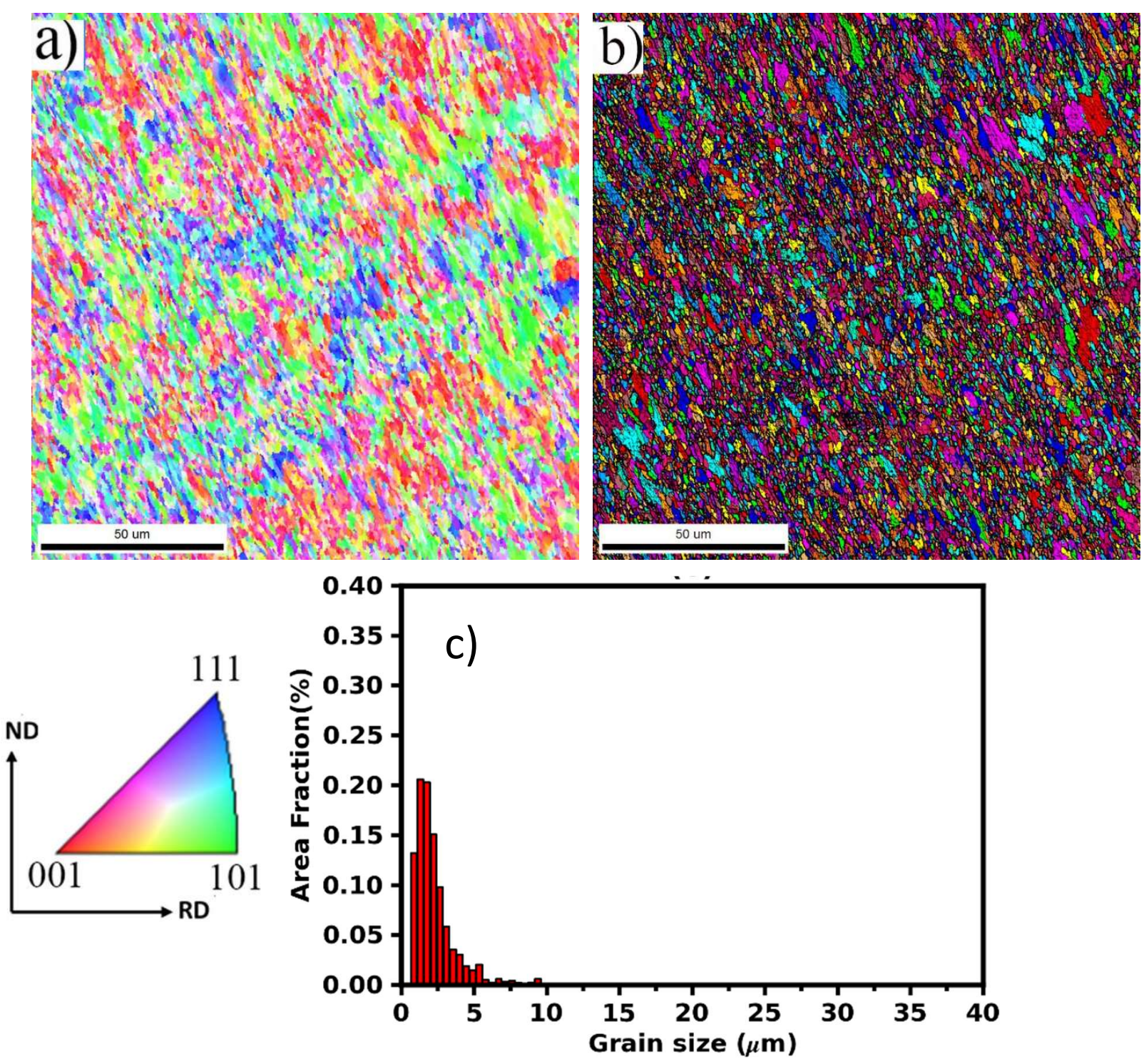

Fig. 8. Grain structure maps of the studied AA1070 alloy obtained by OIM processed by fourth Micro/meso-forming pass: (a) EBSD-IPF map in the (RD-ND) plane, (b) orientation map (using Euler colouring), and (c) the corresponding grain size distribution of (a).

It is interesting to assess the misoriention of all boundaries in the structure with proceeding deformation passes. An increase of misorientation angles as a function of the number of micro/meso-ECAP passes is clearly observed in the boundary misorientation angle distribution measured by EBSD, as shown in Fig. 9. The fractions of the boundary distributions in Fig. 9, reveal that large fractions of high-angle boundaries in the sample processed by micro/meso-ECAP are induced during severe straining in subsequent ECAP passes. LAGBs have decreased 
drastically, while HAGBs increased. For instance, the fractions of HAGBs are increased from 16.8 to 50.8 pct with proceeding the deformation from the first pass to the fourth pass, respectively. Hence, ultrafine grain structure with high-angle boundaries is achieved following 4 pressing passes in the micro/meso-ECAP forming of the studied material. It was reported that the fraction of HAGBs successively increases with the number of SPD passes [31]. It is well established that the evolution of grain boundaries is significantly enhanced by two mechanisms during hot deformation of materials, i.e., dynamic recrystallization DRX and dynamic recovery DRV. For instance, Lin et al. $[\underline{32}, \underline{33}]$ reported the evolution of grain boundaries through DRX and DRV in a Sr-modified Al$\mathrm{Si}-\mathrm{Mg}$ alloy and in a nickel-based superalloy through EBSD analysis of the microstructural evolution. However, in the present work, the evolution of grain boundaries is promoted by a different mechanism, grain subdivision. All these mechanisms are attributed to the deformation stored energy during straining, which represent the driving force for grain boundary evolution.
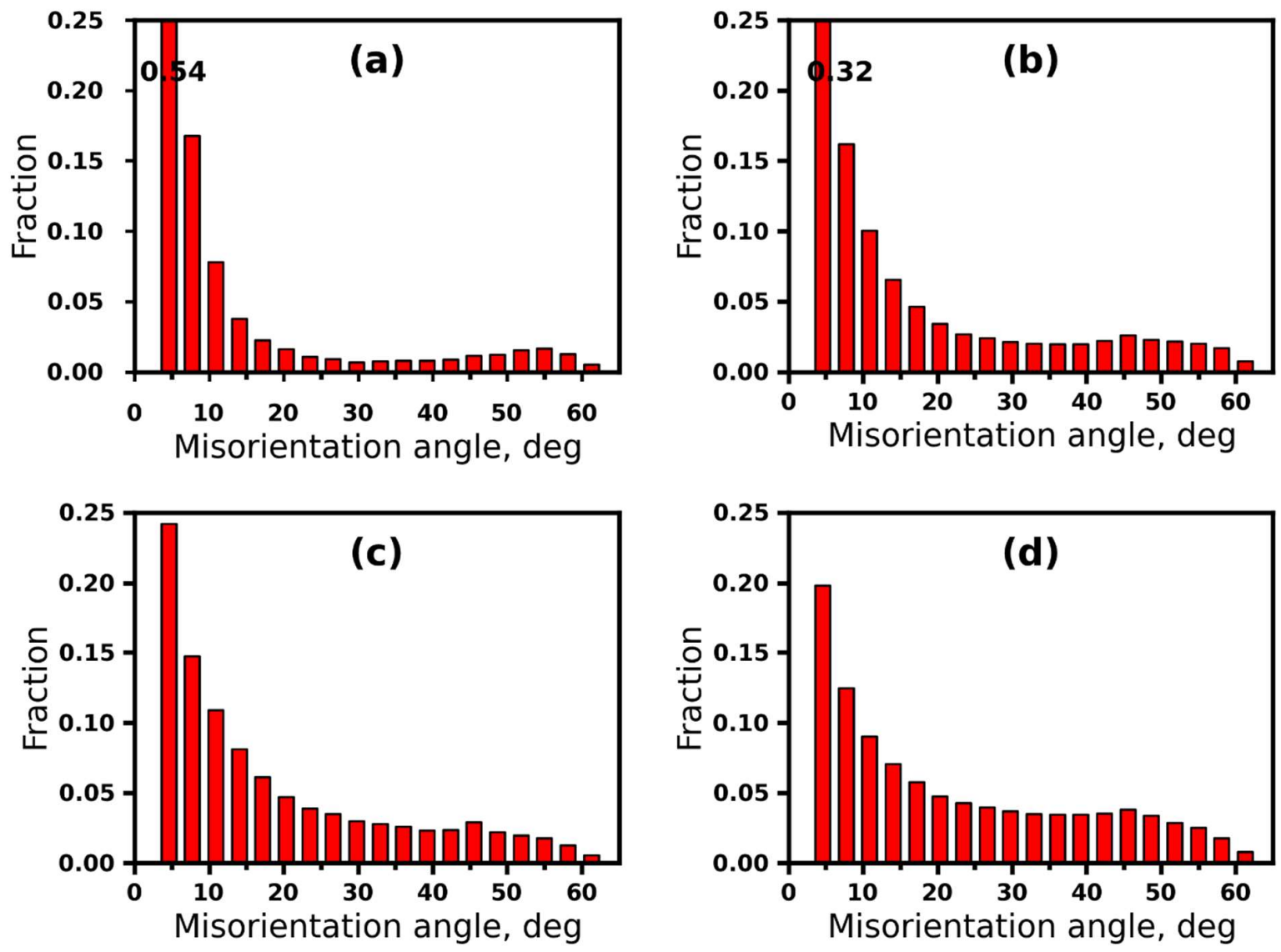

Fig. 9. Distributions of the boundary misorientation angles on the (RD-ND) plane in corresponding the EBSD data of the 4 passes samples. 
To analyze the microstructural refinement and the progressive increase in the boundary misorientation angles during ECAP forming, the number of the applied ECAP passes dependences of the grain size and hardness are plotted in Fig. 10. As seen in Fig. 10, the grain size and hardness are strongly dependent on the number of applied ECAP passes. The grain size is decreased from $20 \mu \mathrm{m}$ in the virgin sample to about $2 \mu \mathrm{m}$ in the sample ECAPed 4 passes, i.e., 90 pct reduction in grain size. In addition, Fig. 10 shows the variation in hardness with the number of ECAP passes. It can be seen that with increasing the number of ECAP passes, the hardness of the processed sample increases. Maximum hardness of $60 \mathrm{Hv}$ is observed for the four-pass ECAP processed sample.

Similarity, Fouad et al. [30] found that a gradual increase in the microhardness of the studied AA 1100 alloy after 4-passes of MCSTE. They found that the corresponding microhardness increased from 30 to $52 \mathrm{Hv}$, i.e., $72 \%$ increase in the average hardness.

It is apparent that the strain hardening in the course of micro/meso-ECAP deformation can readily be followed by hardness changes. Consequently, it is reasonable to assume two operating strengthening mechanisms during micro/meso-forming, i.e., grain/subgrain strengthening due to grain refinement and dislocation strengthening due to dislocation generation. Thus, it is interesting to calculate the dislocation density with proceeding the forming passes.

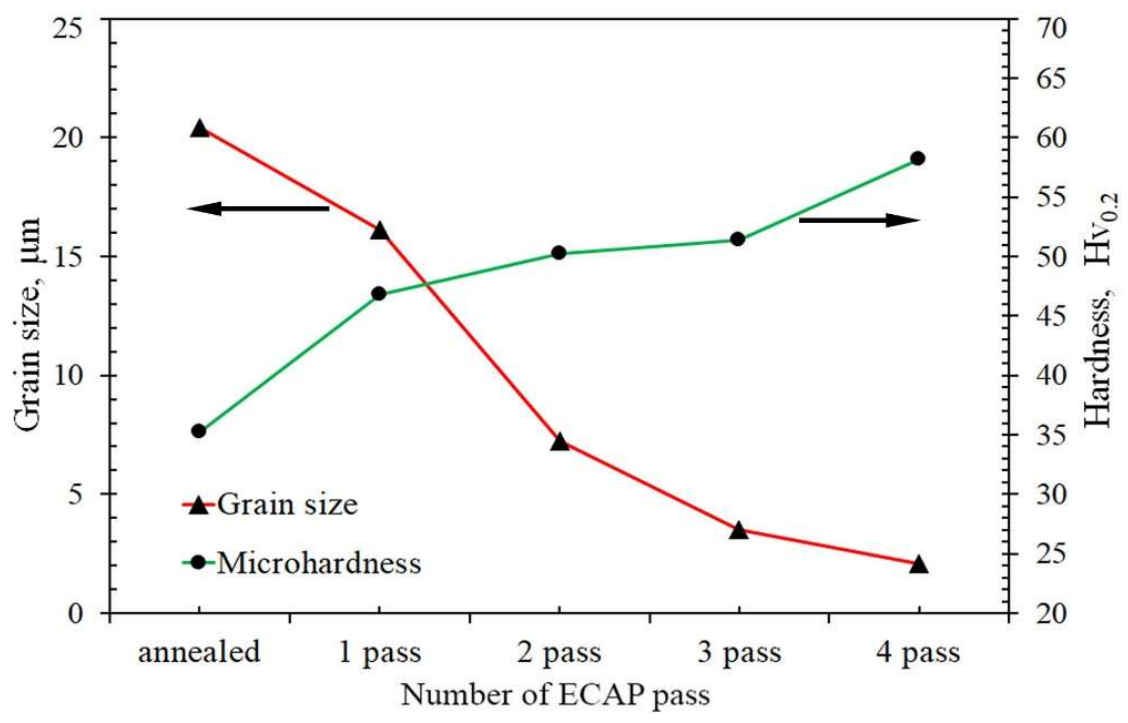

Fig. 10. Number of micro/meso-ECAP pass dependence of the grain size and hardness of the studied material after micro/meso-ECAP forming. 
Fig. 11 shows both the dislocation density and the fraction of LAGBs as a function of the number of ECAP passes. The dislocation density values enhanced during the different ECAP passes were calculated from XRD patterns using the modified Williamson-Hall (mWH) method [34].

It can be notably seen that the dislocation density, $\rho$, reaches its peak at the first ECAP pass with a value of $1.8 \times 10^{14}$ dislocations $/ \mathrm{m}^{-2}$, however, the corresponding $\rho$ for the undeformed sample is about $0.8 \times 10^{14}$ dislocations $/ \mathrm{m}^{-2}$. This behaviour is expected and can be explained by the generation and multiplication of dislocations that occur during the press straining of ECAPed material. It is interesting to observe that the $\rho$ values decrease upon the subsequent micro/mesoECAP deformation. It is well known that the continuous nucleation of dislocation from FrankReed sources generally relies extensively on the plastic deformation. However, the limiting factor is that the dislocation source could not exceed the grain size [35]. It is reasonable to assume that deceasing the dislocation density is caused by microstructural refinement since HAGBs tend to absorb dislocations

The fraction of LAGBs with the misorientation angles $\left(2^{\circ}-\mathbf{5}^{\circ}\right)$ follows the same trend of dislocation density. The fraction of LAGBs $\left(2^{\circ}-\mathbf{5}^{\circ}\right)$ shows a maximum value at the first pass and drastically decreases from $53.4 \%$ at the first pass to $19.2 \%$ at the fourth pass. However, the fraction of LAGBs of higher misorientation angles $\left(5^{\circ}-15^{\circ}\right)$ reveals an opposite trend. As seen, this fraction increases with the number of ECAP passes.

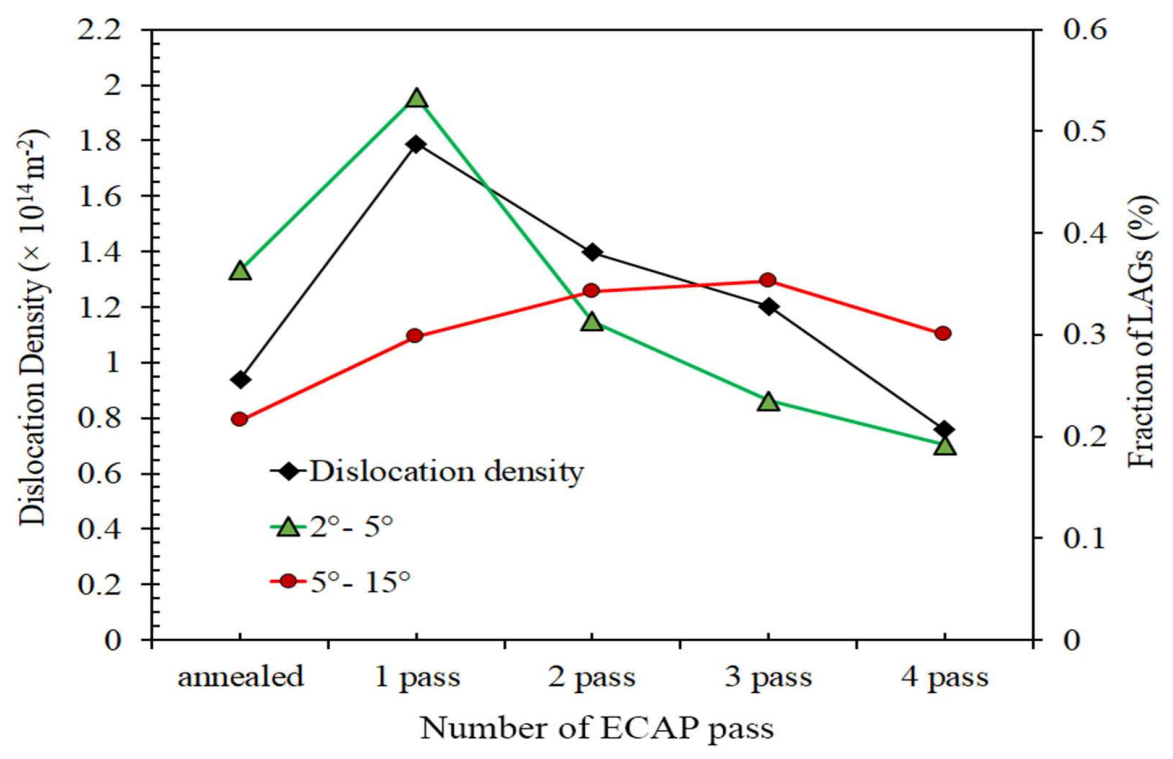

Fig. 11. The dislocation density and the fraction of LAGBs of the AA1070 alloy after different passes of Micro/meso-forming. 


\subsection{Texture analysis}

The texture intensity of both the starting texture and the ECAPed AA1070 alloy in the (RD-ND) plane obtained from (111) inverse pole figures are shown in Fig. 12. It is worth noting that the measurement area of the sample texture is coincidental with the one used for the measurement of microstructure for each ECAP pass as mentioned before.

As can see, Fig. 12(a), the pole figure of the starting alloy demonstrates that the texture comprises strong $<100>$ fiber with a weak $<111>$ fiber and the fiber axis is parallel to the extrusion direction. Fig. 12(f) introduces the ideal shear orientations for FCC samples produced by ECAP in the flow plane [36]. After the first ECAP pass, the initial texture was remarkably changed in orientation distribution and the component of $\mathrm{C}_{\theta}, \mathrm{B}_{\theta} / \overline{\mathrm{B}}_{\theta}$ and a weak $\mathrm{A}_{\theta}^{*}$ can be observed, however, the components of $A_{\theta} / \bar{A}_{\theta}$ are almost absent, see Fig. 12(b). After 3 passes, Fig. 12(d), the $B_{\theta} \bar{B}_{\theta}$ tends to be strengthened, whereas $A_{\theta}^{*}$ components tends to weaken after strengthening on the second pass, Fig. 12(c), and $A_{\theta} / \bar{A}_{\theta}$ components are still missing but after the 4 pass, the $A_{\theta} / \bar{A}_{\theta}$ are likely to appear. However, a weakening trend for all ideal shear-type components can be noticed in Fig. 12(e), this happens as a result of increasing the accumulative strain that develops a net spread of the orientation components due to generating new fine grains and a consequently an overall weakening in the texture intensity occured. The occurrence of texture weakening with proceeding the material deformation to four micro/meso-ECAP passes is in good agreement with results of the other reports presented before in [37-39]. 

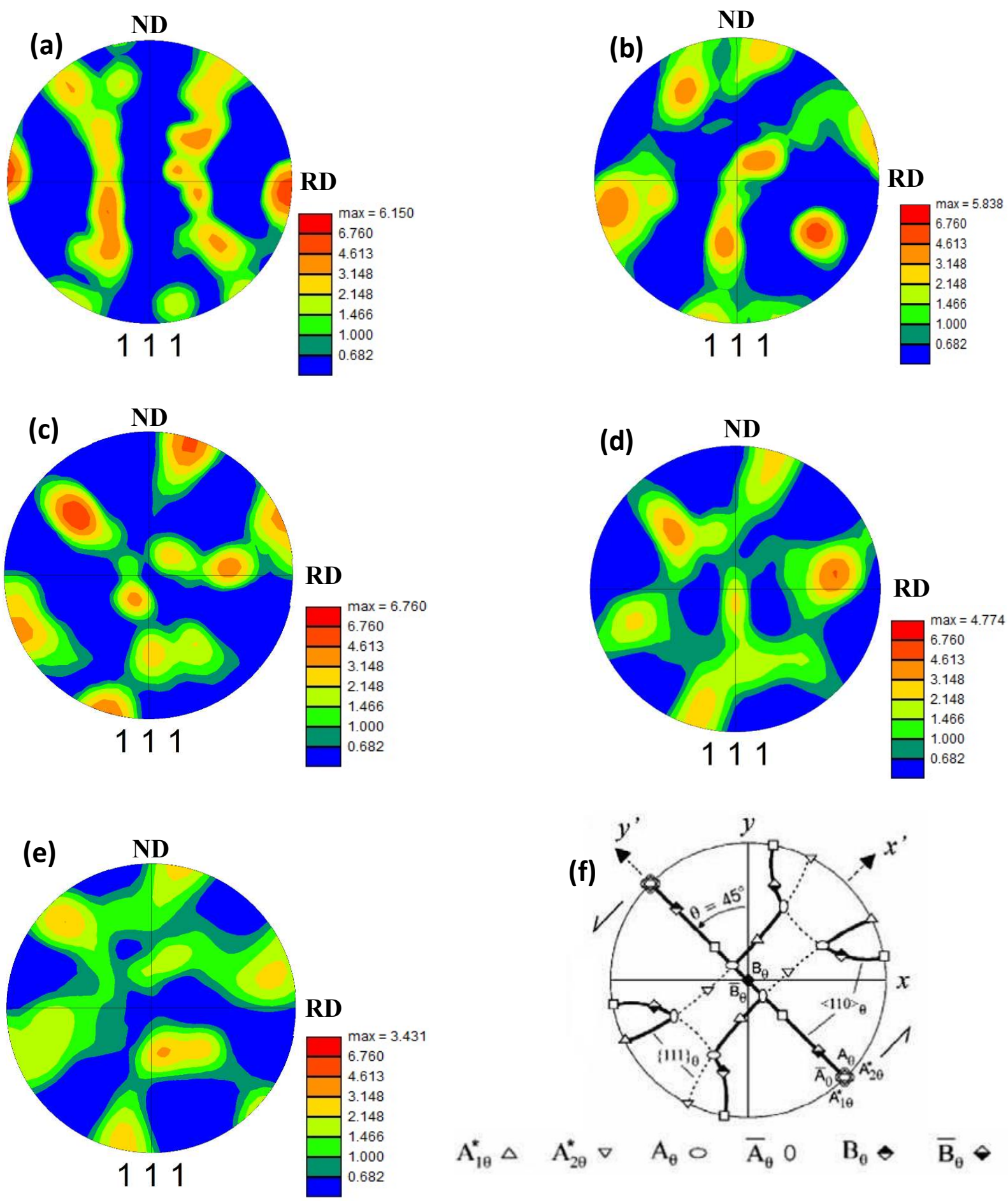

$$
A_{1 \theta}^{*} \Delta \quad A_{2 \theta}^{*} \nabla \quad A_{\theta} \circ \quad \bar{A}_{\theta} \circ \quad B_{\theta} \diamond \quad \bar{B}_{\theta} \diamond \quad C_{\theta} \square
$$

Fig. 12. (1 111 1) Pole figures of the textures on the longitudinal direction : (a) starting alloy, (b) 1pass, (c) 2passes, (d) 3passes, (e) 4passes and (f) (1 111 ) pole figure showing the main ideal shear orientations (symbols) and its components) in ECAP [ㅎ6]. 


\section{Discussion}

The experimental results provide a thorough investigation concerning the grain refinement mechanism in AA1070 alloy subjected to four passes by micro/meso-scale ECAP using route $\mathrm{B}_{\mathrm{C}}$. To demonstrate the level of grain refinement, a summary of the microstructural observations are shown in table 1 . The average grain size and the average misorientation angles were obtained from the EBSD analysis of the microstructure evolution at the different ECAP passes, Fig. (4-8) and Fig.9. As seen in Table 1, the grain structure has undergone significant refining through the subsequent ECAP passes. The grain size is refined from $20.4 \mu \mathrm{m}$ for the annealed structure to 2.08 um for the ECAPed sample 4 passes. The microstructural refinement plays a significant role in the strengthening of material that can be explained by the grain boundary strengthening effect [40]. Consequently, the deformation load in the punch loading curves, see Fig. 2, increases with proceeding the pressing to the subsequent ECAP passes. This is because the huge number of smaller grain sizes introduce many grain boundaries, which act as a barrier for the slipping during further deformation and consequently, the work hardening occurs. Thus, the hardness property of the ECAPed material, as shown in Fig. 10, increases significantly with the progressing increasing of micro/meso-ECAP deformation. These enhancements are grain size-related strengthening.

Table 1 the mean grain size, and percent of the HAGBs and LAGBs of the annealed and ECAPed AA1070 samples in the (RD-ND) plane.

\begin{tabular}{ccccc}
\hline condition & $\begin{array}{c}\text { Average } \\
\text { grain size } \\
(\boldsymbol{\mu m})\end{array}$ & $\begin{array}{c}\text { HAGBs }(\%) \\
\geq \mathbf{1 5}^{\circ}\end{array}$ & $\begin{array}{c}\text { LAGBs (\%) } \\
\mathbf{2}^{\circ} \leq \boldsymbol{\theta}<\mathbf{1 5}^{\circ}\end{array}$ & $\begin{array}{c}\text { Average } \\
\text { misorientation } \\
(\mathbf{d e g r e e})\end{array}$ \\
\hline Annealed & 20.44 & 42.1 & 57.9 & $19.57^{\mathbf{0}}$ \\
\hline $\mathbf{1}^{\text {st }}$ pass & 16.10 & 16.8 & 83.2 & $10.39^{\circ}$ \\
\hline $\mathbf{2}^{\text {nd }}$ pass & 7.22 & 34.4 & 65.6 & $16.07^{\circ}$ \\
\hline $\mathbf{3}^{\text {rd }}$ pass & 3.78 & 41.2 & 58.8 & $17.47^{\circ}$ \\
\hline $\mathbf{4}^{\text {th }}$ pass & 2.08 & 50.8 & 49.2 & $20.92^{\circ}$ \\
\hline
\end{tabular}

During severe plastic deformation in the micro/meso-ECAP technique, the present material AA1070 of high stacking fault energy (SFE), is a highly strained structure with accumulative shear strain due to the progressive deformation. Therefore, a substantial mechanism in the grain structure during micro/meso-ECAP passes, i.e., grain subdivision is effectively activated [41-44]. 
Thus, it can be said that high densities of dislocations are produced as a result of the strong shear force through ECAP process. These dislocations, which are originally distributed through the grains, rearrange and set together into dislocation cells to lessen the total strain energy, as well as a misorientation evolves between the cells, forming subgrain boundaries. And this can be explained by increasing the fraction of LAGBs $\left(2^{\circ}-5^{\circ}\right)$ after 1st ECAP pass, see, Fig. 11.

With further deformation, these subgrains are increased by a continuous absorbing of dislocations to strengthen and tend to rotate into HAGBs, typically with an equiaxed shape [45]. Therefore, the microstructure evolution of UFG during micro/meso-scale ECAP process involves of formation of LAGBs and then gradual transformation of LAGBs into UFGs with HAGBs. The increase of HAGBs with respect to number of ECAP passes is induced due to two main reasons [44, 45]: (1) formation of new HAGBs through grain subdivision mechanism, and (2) formation of deformation bands at lower strains, which leads to grain distortion, consequently, increasing in HAGBs with greater strains.

Further supporting evidence on the aforementioned, a high magnification EBSD map (step size 50 $\mathrm{nm}$ ) of the processed microstructure after fourth ECAP pass on the plane (RD-ND) is shown in Fig. 13. The orientation map, Fig. 13(a), reveals fragmenting of the ECAPed grains to subgrains, i.e., the existence of substructure inside the processed grains, as indicated by the white circles. The boundary misorientation angles along the white line indicated in Fig. 13(a) is plotted in Fig. 13(b). It can be seen that the misorientations across the grain boundaries are mostly high-angle boundaries, i.e. $>15^{\circ}$. The microstructure shows that grain subdivision mechanism is more active as a microstructural refining mechanism in the micro/meso-ECAP deformation.

For that sense, these numerous fine grains characterized by HAGBs are accompanied by different crystallographic orientations, thus leading to developing a weak texture. In contrast, when the texture is strong as in the starting material, this means that there is a preferred orientation for most crystallines in the sample and minor number of crystallines diverge from that orientation. In the ealier ECAP passes, the misorientations between the grain boundaries are still in the low angle range, and consequently, the total fraction of LAGBs increase and as a result, the crystallographic orientations of numerous grains turn out to be close. By increasing the ECAP passes, the texture weakens in the flow plane due to developing new fine grains with divergent orientations.

It is apparent from the observations in the present work that the micro/meso-ECAP process results in a high shear strain in the processed structure. Consequently, grain subdivision mechanism 
operates to accommodate the severe plastic deformation at the grains interior, and ultrafine-grained structure is achieved.
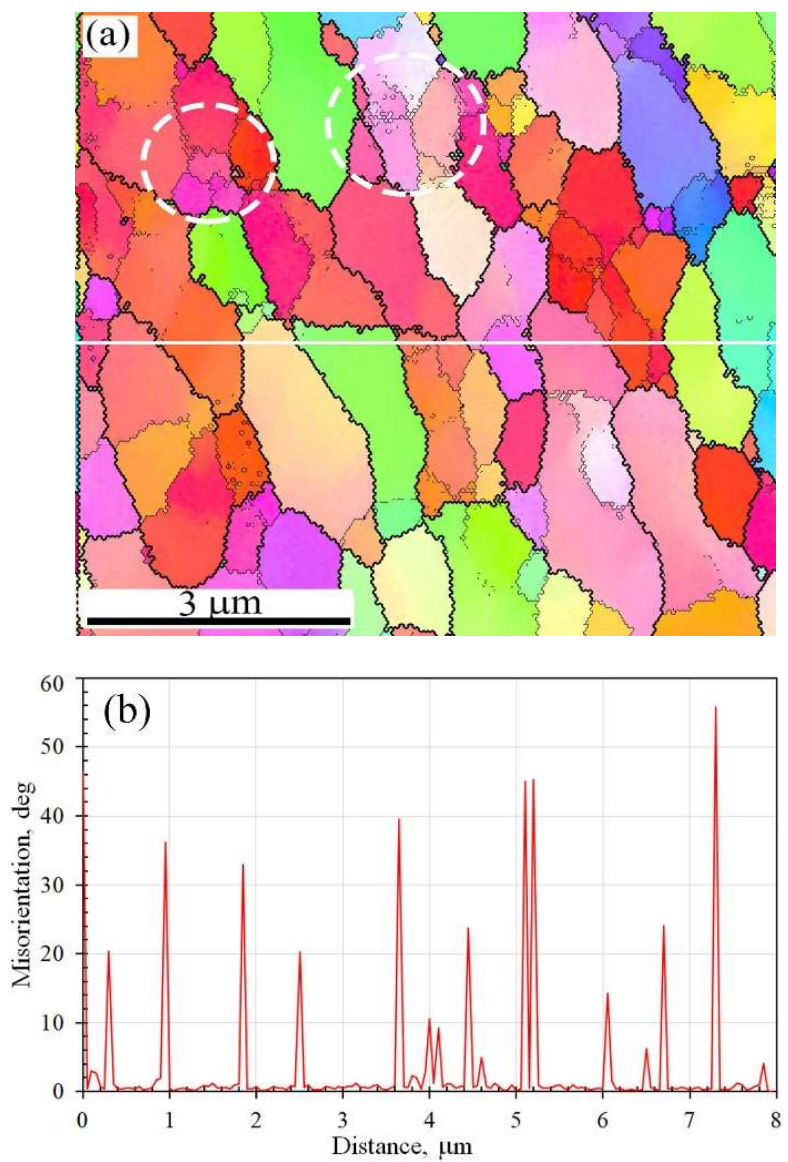

Fig. 13. (a) EBSD-orientation map after the fourth pass of the micro/meso-ECAP deformation of AA1070 alloy in the (RD-ND) plane and (b) misorientation profile corresponding to the white line in (a).

\section{Conclusion}

The most relevant results of the present work concerning the deformation processes and microstructural features in AA1070 alloy processed by micro/meso-scale equal channel angular pressing can be briefly summarized as follows:

1. Extensive localized shear bands have been observed to form in many grains at the first ECAP pass. These bands are microscopic subdivision characteristics in the microforming deformation of the studied material. 
2. The HAGB fractions are significantly affected by the micro/meso-ECAP pressing passes. At higher ECAP passes, a higher HAGB fraction with a low density of dislocation is enhanced in the ECAPed alloy.

3. The strain hardening during ECAP deformation of the processed material continues to progress according to the Hall-Petch relationship with grain size reduction at higher ECAP passes. Consequently, the hardness increases with the ECAP passes.

4. The higher degree of grain refinement of the studied material processed by the micro/meso forming is attributed to the grain subdivision mechanism. Since the grain size was refined from $20 \mu \mathrm{m}$ to $2 \mu \mathrm{m}$ via route $B_{C}$ due to large strains induced in the processed material.

5. The texture evolution during the microforming deformation of AA1070 alloy affects the grain subdivision and contributes to the formation of HAGB, i.e., promoting the fragmented structure during micro/meso ECAP forming.

\section{Acknowledgement}

One of the authors (W.A) is pleased to acknowledge the financial support from the Missions Sector-Higher Education Ministry, Egypt, and the Japan International Cooperation Agency (JICA) through this work.

\section{Refernces:}

1 T. Aida, K. Matsuki, Z. Horita and T. G. Langdon, Scripta materialia 44, 575-579 (2001).

2 Z. Yao, G.-Y. Kim, L. Faidley, Q. Zou, D. Mei and Z. Chen, Journal of Materials Processing Technology 212, 640-646 (2012).

3 U. Engel and R. Eckstein, Journal of Materials Processing Technology 125, 35-44 (2002).

4 Z. Yao, G.-Y. Kim, L. Faidley, Q. Zou, D. Mei and Z. Chen, Journal of Manufacturing Science and Engineering 133, 061009 (2011).

5 Z. Xu, L. Peng, P. Yi and X. Lai, International Journal of Mechanical Sciences 150, 265-276 (2019).

6 J. Han, W. Zheng, G. Wang and M. Yu, The International Journal of Advanced Manufacturing Technology 95, 1127-1133 (2018).

7 L. Peng, P. Hu, X. Lai, D. Mei and J. Ni, Materials \& design 30, 783-790 (2009).

8 Z. Xu, L. Peng and E. Bao, Journal of Materials Processing Technology 252, 407-420 (2018).

9 T. Furushima, H. Tsunezaki, K.-i. Manabe and S. Alexsandrov, International Journal of Machine Tools and Manufacture 76, 34-48 (2014).

$10 \quad$ W. Chan and M. Fu, The International Journal of Advanced Manufacturing Technology 62, 9891000 (2012).

11 A. Rosochowski, W. Presz, L. Olejnik and M. Richert, The International Journal of Advanced Manufacturing Technology 33, 137-146 (2007). 
W. Chan, M. Fu and J. Lu, Materials \& Design 32, 198-206 (2011).

C. Keller, E. Hug and D. Chateigner, Materials Science and Engineering: A 500, 207-215 (2009).

C. Keller and E. Hug, Materials Letters 62, 1718-1720 (2008).

N. Krishnan, J. Cao and K. Dohda, Journal of Manufacturing Science and Engineering 129, 669676 (2007).

M. Yeh, H. Lin, H. Lin and C. Chang, Journal of materials processing technology 180, 17-22 (2006).

W. Kim and Y. Sa, Scripta Materialia 54, 1391-1395 (2006).

J. Xu, L. Shi, C. Wang, D. Shan and B. Guo, Journal of Materials Processing Technology 225, 375384 (2015).

T. G. Langdon, Acta Materialia 61, 7035-7059 (2013).

V. Segal, V. Reznikov, A. E. Drobyshevskiy and V. Kopylov, Russian Metallurgy 1, 115-123 (1981). M. Kawasaki, Z. Horita and T. G. Langdon, Materials Science and Engineering: A 524, 143-150 (2009).

A. Veveçka, M. Cabibbo and T. G. Langdon, Materials characterization 84, 126-133 (2013). S. Wronski, J. Tarasiuk, B. Bacroix, K. Wierzbanowski and H. Paul, Materials Characterization 78, 60-68 (2013).

Z. Horita, T. Fujinami and T. G. Langdon, Materials Science and Engineering: A 318, 34-41 (2001). P.-L. Sun, P.-W. Kao and C.-P. Chang, Metallurgical and Materials Transactions A 35, 1359-1368 (2004).

S. Wu, Z. Wang, C. Jiang, G. Li, I. Alexandrov and R. Valiev, Materials Science and Engineering: $A$ 387, 560-564 (2004).

P. Prangnell, J. R. Bowen and P. Apps, Materials Science and Engineering: A 375, 178-185 (2004).

D. Hughes and N. Hansen, Acta materialia 45, 3871-3886 (1997).

P. Sun, P. Kao and C. Chang, Scripta Materialia 51, 565-570 (2004).

D. Fouad, W. El-Garaihy, M. Ahmed, M. E.-S. Seleman and H. Salem, Materials Science and Engineering: A 737, 166-175 (2018).

T. Koizumi and M. Kuroda, Materials Science and Engineering: A 710, 300-308 (2018).

Y. Lin, D.-G. He, M.-S. Chen, X.-M. Chen, C.-Y. Zhao, X. Ma and Z.-L. Long, Materials \& Design 97, 13-24 (2016).

Y. Lin, S.-C. Luo, L.-X. Yin and J. Huang, Journal of Alloys and Compounds 739, 590-599 (2018).

G. Williamson and W. Hall, Acta metallurgica 1, 22-31 (1953).

R. Misra, B. R. Kumar, M. Somani and P. Karjalainen, Scripta Materialia 59, 79-82 (2008).

I. J. Beyerlein and L. S. Tóth, Progress in Materials Science 54, 427-510 (2009).

B. Tolaminejad and K. Dehghani, Materials \& Design 34, 285-292 (2012).

E. A. El-Danaf, Materials Science and Engineering: A 492, 141-152 (2008).

S. G. Chowdhury, A. Mondal, J. Gubicza, G. Krállics and Á. Fodor, Materials Science and Engineering: A 490, 335-342 (2008).

M. Shaeri, M. Shaeri, M. Ebrahimi, M. Salehi and S. Seyyedein, Progress in Natural Science: Materials International 26, 182-191 (2016).

N. Hansen, X. Huang and G. Winther, Metallurgical and Materials Transactions A 42, 613-625 (2011).

G. Winther, X. Huang and N. Hansen, Acta materialia 48, 2187-2198 (2000).

Q. Liu, N. Hansen, C. Maurice and J. Driver, Metallurgical and Materials Transactions A 29, 23332344 (1998).

Q. Ma, W. Mao, B. Li, P. Wang and M. Horstemeyer, Light Metals 2013, p. 351-356, Springer, Place PUblished (2016).

A. Mishra, B. Kad, F. Gregori and M. Meyers, Acta Materialia 55, 13-28 (2007). 


\section{Figure captions:}

Fig. 1. Micro/meso-scale ECAP die: (a) the employed fabricated die, (b) the Schematic depiction of the die.

Fig. 2. Load-stroke curves for the ECAPed Al 1070: (a) first pass, and (b) fourth pass.

Fig. 3. Typical appearance of the ECAPed AA1070 samples.

Fig. 4. Microstructure of the starting metal Al 1070: (a) SEM-EBSD-IPF map, (b) the corresponding grain size distribution of (a), and (c): The relative frequencies of the boundary misorientation angles. The EBSD data were acquired using a $0.3 \mu \mathrm{m}$ step size.

Fig. 5. EBSD maps of the grain structure maps of AA1070 alloy obtained after the first pass of micro/meso-forming: (a) EBSD-IPF map in the (RD-ND) plane, (b) orientation map (using Euler colouring), and (c) the corresponding grain size distribution of (a).

Fig. 6. Grain structure maps of the studied AA1070 alloy obtained by OIM processed by second micro/meso-forming pass: (a) EBSD-IPF map in the (RD-ND) plane, (b) orientation map (using Euler colouring), and (c) the corresponding grain size distribution of (a).

Fig. 7. Grain structure maps of the studied AA1070 alloy obtained by OIM processed by third Micro/meso-forming pass: (a) EBSD-IPF map in the (RD-ND) plane, (b) orientation map (using Euler colouring), and (c) the corresponding grain size distribution of (a).

Fig. 8. Grain structure maps of the studied AA1070 alloy obtained by OIM processed by fourth Micro/meso-forming pass: (a) EBSD-IPF map in the (RD-ND) plane, (b) orientation map (using Euler colouring), and (c) the corresponding grain size distribution of (a).

Fig. 9. Distributions of the boundary misorientation angles on the (RD-ND) plane in corresponding the EBSD data of the 4 passes samples.

Fig. 10. Number of micro/meso-ECAP pass dependence of the grain size and hardness of the studied material after micro/meso-ECAP forming.

Fig. 11. The dislocation density and the fraction of LAGBs of the AA1070 alloy after different passes of Micro/meso-forming.

Fig. 12. (1 111 1) Pole figures of the textures on the longitudinal direction: (a) starting alloy, (b) 1pass, (c) 2passes, (d) 3passes, (e) 4passes and (f) (1 111 ) pole figure showing the main ideal shear orientations (symbols) and its components) in ECAP [36].

Fig. 13. (a) EBSD-orientation map after the fourth pass of the micro/meso-ECAP deformation of AA1070 alloy in the (RD-ND) plane and (b) misorientation profile corresponding to the white line in (a). 
